The BMJ

Cite this as: BMJ 2021;373:n943 http://dx.doi.org/10.1136/bmj.n943 Published: 09 April 2021
NEWS ANALYSIS

\section{What did the Commission on Race and Ethnic Disparities say on health?}

\section{A government commissioned review that found "no evidence of systemic or institutional racism" in the UK has been heavily criticised. Gareth lacobucci examines what it said on health \\ Gareth lacobucci \\ In its much criticised report published on 31 March, ${ }^{1}$ the Commission on Race and Ethnic Disparities \\ What else did it say on socioeconomic disparities?} included a detailed chapter on health disparities. The commission said that it had identified challenges in obtaining consistent ethnicity data across different health conditions, but it based its findings on the available evidence.

\section{What do the data on life expectancy show?}

The report concluded that ethnic minority groups have better outcomes than the white population. It cited data from Scotland showing that life expectancy is generally higher in the larger ethnic minority populations than in the majority white Scottish group, particularly among people from Indian, Pakistani, and Chinese ethnic groups, and despite higher levels of deprivation.

Life expectancy data for England are not published, but the report noted that, in 2019, age standardised mortality rates were $26 \%$ lower in black and South Asian people than in white people, again despite higher deprivation. The commission said that there were limited data on healthy life expectancy by ethnicity, but it cited a paper from Scotland using 2011 census data which showed that, despite having longer life expectancy than white people, women from Pakistani and Indian ethnic groups had a shorter healthy life expectancy.

\section{What did the report say about disparities in covid-19?}

The commission highlighted reports from the government's race disparity unit, ${ }^{23}$ which concluded that most of the increased risk of infection and death from covid-19 among people from ethnic minorities was explained by socioeconomic factors and that inequalities in outcomes "are driven by risk of infection, as opposed to ethnicity alone being a risk factor."

But writing in the Guardian, ${ }^{4}$ Michael Marmot, global expert on inequalities, argued that this ignored the role that structural racism plays, as highlighted in his 2020 report. ${ }^{5}$ Marmot acknowledged that the "shockingly high" covid-19 mortality rates among black, Bangladeshi, Pakistani, and Indian people in Britain "can be attributed to living in deprived areas, crowded housing, and being more exposed to the virus at work and at home," but he argued that "these conditions are themselves the result of longstanding inequalities and structural racism.”
The commission noted that Marmot's landmark 2010 review on health inequalities found variations by ethnic minorities but "did not answer why the social determinants of health are unequally distributed between different racial and ethnic groups."

The commission added, "Some ethnic minority groups have higher life expectancies and lower risks of many cancers than the white majority population, despite higher levels of deprivation. These factors are complex, but this is no way an overall negative picture for ethnic minority groups.”

However, Marmot said ${ }^{4}$ that the commission had quoted his work selectively, ${ }^{6}$ by failing to mention "explicit reference to race/inequality in two reports from our institute last year." He said that in 2010 he had thought that most ethnic differences in health could be explained by socioeconomic characteristics, but he changed his view after chairing the Commission of the Pan American Health Organization on Equity and Health Inequalities in the Americas. "It highlighted the effects of colonialism and structural racism, and emphasised the overwhelming need to deal with such racism in combating the social determinants of health inequalities," said Marmot.

Mala Rao, director of the Ethnicity and Health Unit at Imperial College London and medical adviser for the Workforce Race Equality Strategy at NHS England, said that the commission's "denial of structural and institutional racism as a key explanatory driver of health and socioeconomic inequalities is deeply troubling." She added, "A huge body of evidence is available which demonstrates this."

\section{Did the commission look at specific diseases?}

Yes. It reported that white people had the highest incidence of all cancers but that incidence and survival rates varied between different ethnic groups. Limited data on survival show that, among ethnic minority groups (not including white minority), survival is generally better or the same for lung, prostate, and colorectal cancers, with mixed evidence for breast cancer.

In terms of cardiometabolic diseases, Pakistani women and Bangladeshi men have the highest risks of cardiovascular disease (CVD) incidence, respectively. CVD prevalence and incidence are lower in Black African and Black Caribbean ethnic groups, 
while men and women from the Chinese ethnic group have lower CVD incidence than white people.

Rates of ischaemic heart disease, hypertension, and diabetes are higher in the South Asian population, and the black population had more hypertension and diabetes but lower ischemic heart disease than the white group. Black people have a 1.5-2.5 times greater risk of having a stroke than white people, and the risk is also 1.5 times greater in South Asian people than white people, particularly those from Pakistani and Bangladeshi ethic groups.

People from the Chinese ethnic group have a lower risk of stroke than white people. Prevalence of type 2 diabetes (when diagnosed biochemically) is three to six times higher in South Asian and black ethnic groups than in white people.

\section{What did it say about obesity?}

In England, when compared to white people, black adults have a consistently higher risk of obesity; adults and children from the Chinese ethnic group have a consistently lower risk; and no consistent patterns were seen in South Asian adults or children relative to white people. The commission identified "significant limitations" in the data, noting that few studies explored and statistically adjusted for potential predictors of obesity among ethnic minority groups.

\section{And lifestyle factors?}

In 2019 the prevalence of smoking among adults in England was $13.9 \%$, but white and mixed ethnicity adults were above this average, and Asian, black, and Chinese adults were below it. White British men and women are the most likely to drink alcohol at hazardous, harmful, or dependent levels, while Asian men and women are the least likely. Self-reported survey data on physical activity show that white adults are most likely to be active, while people of Asian ethnicity are least likely.

\section{Did it examine genetics and ethnic disparities?}

The report acknowledges "clear ethnic differences in risk" for diseases such as cancer, diabetes, and obesity, but it concludes that genetics make only a "modest" contribution to these, aside from some exceptions such as the higher incidence of prostate cancer in black populations. It notes that data on genetic variations in common diseases across ethnic groups are limited and that ethnic minorities are under-represented in clinical trials.

\section{What about mental health?}

The commission recognised advice from experts "that mental ill health has little to do with genetic predisposition but rather is to do with adverse social circumstances, including racism and hardship." It highlighted the Wessely review's ${ }^{7}$ finding that black people were eight times more likely to be subjected to community treatment orders than white people and were four times more likely to be detained. But it added, "Such disparity is often taken as evidence of racism. However, it must be benchmarked against disparity in the prevalence of mental illness," citing evidence showing significantly higher risks of diagnosed schizophrenia among ethnic minorities, particularly in black groups.

Marmot said, "It is surprising that the authors are so ready to dismiss structural racism when they quote, 'experts advise us that mental ill health has little to do with genetic predisposition but rather is to do with adverse social circumstances, including racism and hardship.' The debate is more than semantic.”
The Royal College of Psychiatrists was also critical. "The report implies that, in the claimed absence of structural or institutional factors, individuals or families are to blame for the negative experiences and discrimination they face," it said. "This is dangerous to communities and goes against the weight of the evidence. The authors have relied on outdated information and selective review of the available evidence to make their recommendations, meaning the methodology, as well as the conclusions, are flawed.”

\section{Are barriers to accessing healthcare mentioned?}

The commission noted that majorities of all ethnic groups reported positive experiences of access to healthcare. It observed a relative lack of satisfaction with GP services among some British Asian people, but it added, "The overall picture suggests that racism and discrimination are not widespread in the health system, as is sometimes claimed, as black groups are more or less equal in their satisfaction to white groups.”

It also highlighted evidence that black and Asian people with mental health needs were less likely to be receiving treatment, but it "does not believe that the evidence it reviewed offers support to claims of discrimination within psychiatry."

\section{What about the huge disparity in maternal mortality?}

The commission emphasised that maternal deaths were rare in the UK, but it noted that poor outcomes were higher in mothers and babies from black and Asian ethnic groups, particularly those born in Asia or Africa, and in women living in the most deprived areas of the country.

It advised that more research into causes in the disparities of maternal mortality should be "one of the highest priorities" for the new Office for Health Disparities (see below). In a joint statement, the co-chairs of the Royal College of Obstetricians and Gynaecologists' Race Equality Taskforce-Edward Morris, Christine Ekechi, and Ranee Thakar-backed this recommendation, but they added, "We were disappointed the report did not note similar concerning trends evident in infant birth outcomes, with black women, for instance, being up to twice as likely to suffer a stillbirth than white women."

\section{Why do we need a new Office for Health Disparities?}

The commission argues that the office's remit should be to "properly target health disparities in the UK, focusing on research, communications and expertise to reduce health inequalities across all groups," working alongside the NHS and across government to reduce inequalities in all groups in the UK. Its work will be substantially broader than that of the NHS Race and Health Observatory, ${ }^{8}$ which was established in 2020 specifically to identify and tackle the health challenges facing people from black and minority ethnic backgrounds.

\section{Where should future research be focused?}

The commission identified the need to recruit more ethnic minorities to trials "in proportion to their future share of the population reflecting demographic changes.” It said that the question of why it was difficult to recruit people from ethnic minorities needed to be answered-"whether this was due to mistrust of biomedical research in minority communities due to historical abuses in other countries, logistical barriers to recruitment, and a lack of diversity in researchers designing and leading these studies." 
Did the commission make any other recommendations?

It reported hearing a "lack of trust" from frontline staff in the ability of the healthcare regulator, the Care Quality Commission (CQC), to understand and consider race disparities in its inspection process. The commission recommended that the Department of Health and Social Care should commission a review into the CQC's approach to scoring employee diversity and inclusion in its inspections, with input from the NHS Workforce Race Equality Strategy team and medical disciplinary bodies.

It also recommended a strategic review of the causes of disparate pay across NHS England and how to tackle them. Rao said that, despite her concerns about the commission's report, "Many of us are hoping that the collective efforts of NHS staff, academics, and system leaders which had already begun to systematically dismantle institutional barriers to race equality in health, healthcare, and in the NHS workforce will nevertheless continue at pace.”

1 Commission on Race and Ethnic Disparities. The report. Mar 2021. https://assets.publishing.service.gov.uk/government/uploads/system/uploads/attachment_data/file/974507/20210331__CRED_Report_-_FINAL_-_Web_Accessible.pdf.

2 lacobucci G. Covid-19: Increased risk among ethnic minorities is largely due to poverty and social disparities, review finds. BMJ2020;371:m4099. doi: 10.1136/bmj.m4099 pmid: 33093063

3 lacobucci G. Covid-19: Outcomes worsened in second wave for Pakistanis and Bangladeshis in England. BMJ2021;372:n572. doi: 10.1136/bmj.n572 pmid: 33637553

4 Marmot M. The Sewell report cited my work-just not the parts highlighting structural racism. Guardian2021 Apr 7. https://www.theguardian.com/commentisfree/2021/apr/07/sewell-reportstructural-racism-research.

5 lacobucci G. Marmot 10 years on: austerity has damaged nation's health, say experts. BMJ 2020;368:m747. doi: 10.1136/bmj.m747 pmid: 32098785

6 Institute of Health Equity. Health equity in England: the Marmot review 10 years on. Feb 2020. http://www.instituteofhealthequity.org/home.

7 Department of Health and Social Care. Modernising the Mental Health Act: increasing choice, reducing compulsion. Dec 2018. https://www.gov.uk/government/publications/modernising-themental-health-act-final-report-from-the-independent-review.

8 NHS Confederation. NHS Race and Health Observatory. https://www.nhsconfed.org/networks/nhsrace-and-health-observatory. 